Article

\title{
Cycling through the Landscape of Advertising in Amsterdam: A Commuters Perspective
}

\author{
Patrick Moore and Marco Helbich *(D) \\ Department of Human Geography and Spatial Planning, Faculty of Geosciences, Utrecht University; \\ Princetonlaan 8a, 3584 CB Utrecht, The Netherlands; patricksmoore91@gmail.com \\ * Correspondence: m.helbich@uu.nl
}

Received: 8 June 2020; Accepted: 14 July 2020; Published: 16 July 2020

\begin{abstract}
This paper examines how outdoor advertising shapes the perception and meaning of commuting for cyclists in Amsterdam (The Netherlands), and how individualised constructions of place arise during the journey. New insights are developed for a sustainable urban policy, whilst challenging consumer research methodologies through an emphasis on urban rhythm. Interviews were enhanced through the use of video cameras, capturing the visual attention of advertisements and recording bodily engagement with the road. In contrast to much academic and industry research, it is found that the reception of advertising landscapes differs significantly between transportation types, with socio-cultural differences specific to Amsterdam also determining distinctions for cyclists. The use of data by advertisers to track the movement of cyclists is a contentious issue, with wider consequences for privacy and consent in urban daily life. This paper breaks new ground for sustainability in cycling, re-evaluating the daily-embodied experience of commercial landscapes for commuter-cyclists.
\end{abstract}

Keywords: commuting cyclists; rhythms; outdoor advertising; consumption; embodied experience

\section{Introduction}

If one navigates through particular cities, the confrontation with outdoor advertisements is almost guaranteed; their presence permeating different surfaces. From posters inside trains, billboards positioned on roadsides, to metro station walls. The proliferation of this form of advertising has a profound effect on the look and feel of a city. Due to the widespread coverage across contemporary cities, Cronin [1] (p. 78) argues that advertisements' impact on the urban landscape is directly implicated in and sown into the "particular social arrangement of structures and flows of people that we call 'a city'.". As part of the fabric we consider urban, it is curious that little work has explored how notions of landscapes are formed by their spatial distribution [1,2].

As a primary way that we "experience, make sense of and remember" [3] (p. 1410) urban landscapes, we address how city dwellers visually derive a sense of place through the interaction of outdoor advertisements whilst moving through space. Degen et al. [4] describe how the material features of designed urban spaces are "producing a city of surfaces, calculated for a primarily visual effect". City landscapes are shown often to be "marketable commodities" [3]; little is said, however, of the empirical experience of commercialised environments-i.e., those containing advertisements. Rather than broadly examining "the city", we explore the daily urban experiences of specific areas containing advertisements, focussing on cyclists. While commercial landscapes have been studied for those perceived by pedestrians [5,6], little has been said for the experience of a cyclist. By drawing attention to the potential that advertising has to shape and influence the personal experience of cycling, we raise critical questions of whether they are detrimental to the encouragement and development of cycling as a sustainable mode of transport. 
By focussing on the practice of cycling, we reverse the "common-sensing of some landscape's" [7] less tangible facets, focussing on the mood and atmosphere of urban space, influenced by proximity, alignment, pace [8], route, form and light $[9,10]$. Cycling offers a unique, embodied experience of urban landscapes [11]; which is to say that visual experiences are multi-sensory, involving the aural, tactile, oral, olfactory and kinaesthetic senses [12-15]. The varying practices of cycling, from rural leisure seekers to urban commuters [13], follow different imperatives, expressing context-specific engagements with urban space. As McKenna and Whatling [16] (p. 4) argue, the "'urban embodiment' of commuter cycling is different to that of commuter drivers, pedestrians, or even leisure cyclists". We investigate the specificity in the embodied experience of commuting cyclists, exploring how the imperative of travelling to and from work becomes entangled with how the outdoor advertising landscapes are perceived.

The paper aims to address the following questions:

(1) What role do the rhythms of urban cycle routes play in shaping the experience of commuting in Amsterdam for those exposed to outdoor advertising?

(2) By highlighting context-specific and embodied experiences of a cyclist, can we better evaluate commercial landscapes for sustainable development?

\section{Cycling through the Advertising Landscape}

Everyday rhythms such as walking, cycling and other forms of mobility, are central to how the city is inhabited [17]. The various lived experiences of commuter cycling are arguably missed in quantitative methodologies (e.g., [11,18]). We reveal a nuanced set of accounts, specific to the social and cultural contexts of a cycle route used by commuters in Amsterdam.

Cyclists commuting each day undergo predictable patterns of activity, the most basic level being the route taken, yet they also negotiate the varied conditions of route duration, timing, traffic tempo, cyclist formations, weather or terrain type. The interaction between the cyclist and urban elements develop distinct "urban rhythms". Urban rhythms usefully describe how structures, such as timetables, routines and social obligations, can shape a person's path through space, but also accounting for "spatial qualities, sensations and intersubjective habits" [19] (p. 2). The concept is instructive for investigating daily time structures and processes that implicitly reproduce the conditions of commuting and negotiating "transport problems and choices" [20] (p. 85). For example, Van Duppen and Spierings [14] compare the daily rhythms of negotiating road space and the inherent management of time schedules for commuting cyclists in Utrecht (NL) with that of the planner's perspective (bound to rigid spatial conceptions of transportation routes).

As urban environments reproduce and transform, people respond to urban processes and forms through an on-going "incremental urbanism" [17] (p. 33). Individual rhythmic improvisations can emerge among cyclists who "tactically learn" [17] the everyday spatial structures between home and work. Brown and Spinney [12] examined the bodily engagement of cyclists in continually sensing the subjective rhythms of the road, highlighting the heightened tension between pedestrians and cyclists on the road with vehicular traffic. On the other hand, the complexity found in daily commutes and frequent exposure to advertising may actually lead to reduced sensitivity of the perceptual memory [21] or a "blasé attitude" [22] (p. 24).

Focusing on rhythms of mobility, Cronin $[1,23]$ shows how advertising companies organise city space and frame people's experience by manipulating rhythms such as commuting. A larger size and amount of billboards are placed in strategic locations based on the flow of people (i.e., highways, pedestrian high streets) or large numbers of static viewers (i.e., bus stops, traffic crossings). Cronin [1], however, applied limited empirical analysis to the way individuals perceive and understand outdoor advertisements or the variation between transportation types. Advertising, rather than a predominantly "spectacular" [5] feature of the landscape, organises city space in a diverse yet mundane manner, marking the "everyday, routine experience of travelling to and around cities" [1], (p. 78). Hence, our focus is on addressing the experiential consequences of everyday travel. This research expands upon the 
questions raised by Cronin on the consequences of commercial urban spaces, with a focus on the individual's embodied experience of movement on a bicycle.

Using ethnographic examination of the experience of walking in shopping malls, Degen et al. [4] derive several concepts aimed at capturing the distinct gaze experienced when in commercial spaces. The "shopping look" apprehends the commercial landscape of malls in a "thicker, focused stare [... ] guided by our sense of touch and smell" [4] (p. 1910). As opposed to the "shopping look", the converse known as the "manoeuvring look" [4] is adopted, that draws little distinction between the surroundings; essentially describing a way of looking when moving through a commercial environment that is distanced and concerned with movement, rather than specific features. Our fieldwork evaluates how the interaction within commercial spaces such as malls, differs from the situated spatial awareness of commercial signs in urban environments designed for transport.

A key practice for advertisers to tap into the commercial rhythms of urban travellers, objectified as consumers, is the goal of synchronisation achieved using measurement techniques-e.g., travel surveys and geodemographic segmentation [24]. These commercial techniques influence the attempt to structure and control daily movement in cities, identifying and regulating rhythmic conventions of individuals and groups. In the Dutch context, to "tap into" the linear rhythms of commuters travelling through certain travel routes, Dutch outdoor advertising research company Buitenreclame-Onderzoek has utilised classification techniques that factor in differences between commuter types (i.e., pedestrian, bicycle, car, bus). The roadside visibility model that has been adopted for cyclists combines the variables for vehicles (i.e., faster speed than pedestrians) as well as those for pedestrians (i.e., much longer run-up time than vehicles). The final output claims that "the final cyclist hit rate was comparable to that of pedestrians and identical in most cases"—a hybrid "pedyclist". Although following a logical connection and given statistical validity, this does not necessarily translate to the lived embodied experience of cycling compared to walking or driving in Amsterdam, or indeed within specific contexts. Jiron [6] describes the personal sense of invasion created by advertisements covering the interior of trains for those commuting. The familiarity, while sitting, of their visual appearance, yet alienation to the calls to action for consumption were linked to the synchronicity and experience of travelling to work. Ethnographic examination such as Jiron's [6], importantly shows how one might feel using particular transportation and what this means for people's understanding of advertisements. Roadside advertisements differ drastically from other formats such as those in trains (see e.g., [3], for the redefinition of urban areas created by outdoor advertisements of differing scales and technologies) and require acknowledgement of what this might mean for users encountering them.

Cycling requires negotiating the unpredictability of other cyclists' movement and alternative crossing patterns [14], adapting to different speeds, subtle body language, gestures and indications. These negotiations alter the ability of cyclists to process urban features, such as advertisements. For instance, the obstruction of view from other cyclists can vary depending on the positioning near traffic lights, space available on a path or volume of traffic. Speed also comes into play, limiting the amount of sensory input the cyclist can handle [8]. These bodily encounters offer various possible experiences, emotions, moods [1] and attitudes, which Pike [25] argues develop localised spatial associations with advertisements. What this suggests, is that rather than individual differences in behaviour in commercial space being linked to age, gender, class or race [21], bodily sensing also plays an important role in the behaviour and perception of advertisements.

The future value to advertisers in measuring and regulating bodily rhythms of moving consumers lies in digital outdoor screens. Real-time data feeds (i.e., temperature activated content) and interactivity (i.e., Wi-Fi and Bluetooth connectivity) has led to the timing and engagement of messages directed to urban dwellers achieving advances in accuracy. The bodily rhythms of urban dwellers are increasingly the target of synchronisation of weather-related advertising. Digital technology is enabling advertising targeting to change the messaging displayed, depending on differences in embodied experience. Here, one sees the efficacy of strategies being adopted by advertisers, and how people's daily 
rhythms are in constant contestation and flux, depending on how visual landscapes are arranged and manipulated for commercial gain.

\section{Materials and Methods}

\subsection{Case Study}

Amsterdam offers the largest coverage of outdoor advertising in the Netherlands [26], yet there is a lack of ethnographic research exploring the context-specific meanings understood by the cities' inhabitants. Cycling is a common form of transportation (perceived as "quasi-natural"), forming part of the Dutch culture in Amsterdam [27]. Research examining how cyclists perceive outdoor advertisements is limited. Methodologies have relied on quantitative regional models of cycle routes, factoring limited environmental variables and personal characteristics. Research was conducted on behalf of advertising companies in order to monetise transportation routes used by cyclists. Traffic counts and road layout measurements (e.g., distance from road, size, luminance, visibility) translate into the classification of advertisement sites and their value to advertisers. Critical analysis has been avoided that explores potentially negative or alternative experiences of cycle routes containing advertisements.

Choosing a select area in Amsterdam containing substantial amounts of advertisements enabled distinguishing the diversity and variety of ways in which advertisements give meaning to space and place [25], dispelling advertising as "space less concepts" [28] (p. 334) unrelated to geographical context. Pike [25] argues that how people respond to advertising depends on "socio-spatial relations and identities and their perceptions of the brand and branding's spatial associations and connotations". The road selected, Amstelveenseweg, is located between two neighbourhoods (Stadionbuurt and Zuidas) within the borough of Amsterdam-Zuid (Figure 1), adjacent to the rapidly developing business district: Zuidas. One end of the route lies at the corner of the Vrije Universiteit (VU)/medical centre, adjoining several other business functions, leading toward central Amsterdam. The other end, Stadionplein, begins at the corner next to the Amsterdam Olympic stadium, alongside a car showroom. The route gives one an immediate impression of functionality; with constant use by vehicles, it contains little housing or greenery. The cycle paths along the route, as is the case for much of Amsterdam, were separate from the road as well as pedestrian paths. These specific cultural features had experiential and social consequences for how the nuances of space were navigated, compared to cycle paths in a different city.

The high number of advertisements ( 81 viewed from one direction along the $1.2 \mathrm{~km}$ stretch) seen along the road is indicative of the densely populated borough, containing the highest average income (see Gemeente Amsterdam Bureau Onderzoek en Statisiek, 2014). The range in type of roadside advertisements along the route varied, each specifically engineered to convey messaging in different ways. While scrolling, "6-sheets" are considered more premium in their positioning, usually not directly next to other advertisement sites, the format with the highest coverage on the route is the roadside "4-sheet", which appeared almost every 10 meters on the route (Figure 2). Although less impactful than the "6-sheet", the "4-sheet" frequency is designed for repetition across one route to reinforce messaging; they are lower down than "6-sheets" so that eye-line is accorded to cyclists; in addition, they show on three sides to both pedestrian/cyclists and to vehicular traffic. One larger sized billboard is located on the route next to the VU building, which is a few meters from the cycle path and elevated to be viewed by large groups of people, known as a "16-sheet". Accordingly, it is positioned next to traffic lights, where groups of cyclists wait and have time to view the messaging. Freestanding pillars, covered by several ads can be seen at several points next to the cycle path. These tend to be closer to the pedestrian section of the pavement rather than the cyclist side. The least frequent yet most effective roadside format is the digital screen positioned next to the cycle path (Figure 2). These are far wider than most poster formats and are angled to display to pedestrians passing and the vehicles behind. They are not always active, and display illuminated high-resolution digital images when activated at specific times. Having evaluated the route (e.g., number of "6-sheet" posters and digital screens), 
we liaised with an Amsterdam-based advertising agency (Centercom), with whom the suitability of this route compared to other areas in the city was conferred. Although possible to comparatively examine several areas in Amsterdam containing outdoor advertisements, one route was selected due to the feasibility of conducting video ethnographic studies which are indeed, time consuming [29].

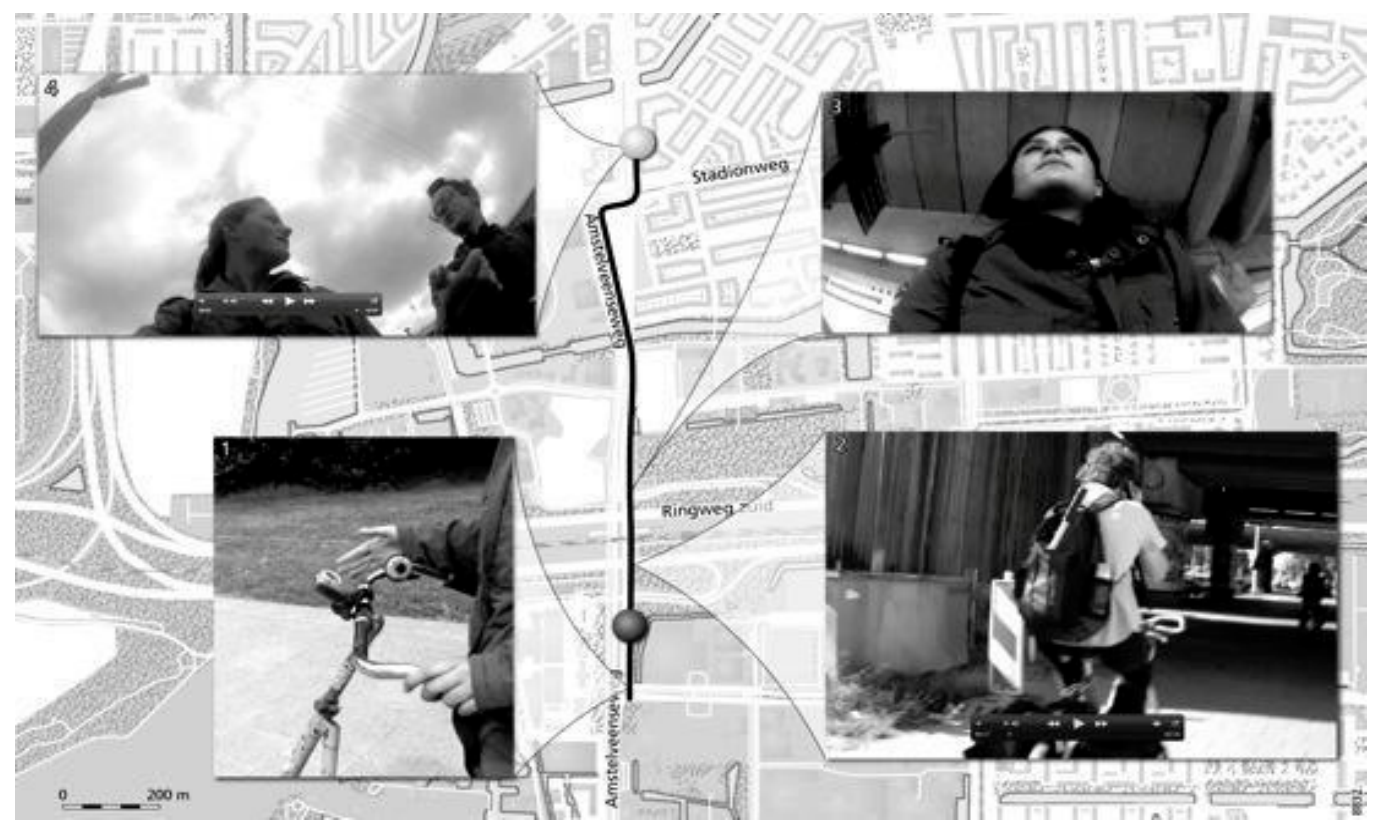

Figure 1. Amstelveenseweg route in Amsterdam. The bottom marker shows the start point for one direction where the camera was attached to the participant's bicycle (1). Along the route, filming from behind (2) and facial view (3) was carried out until the end, where the interview commenced (4).

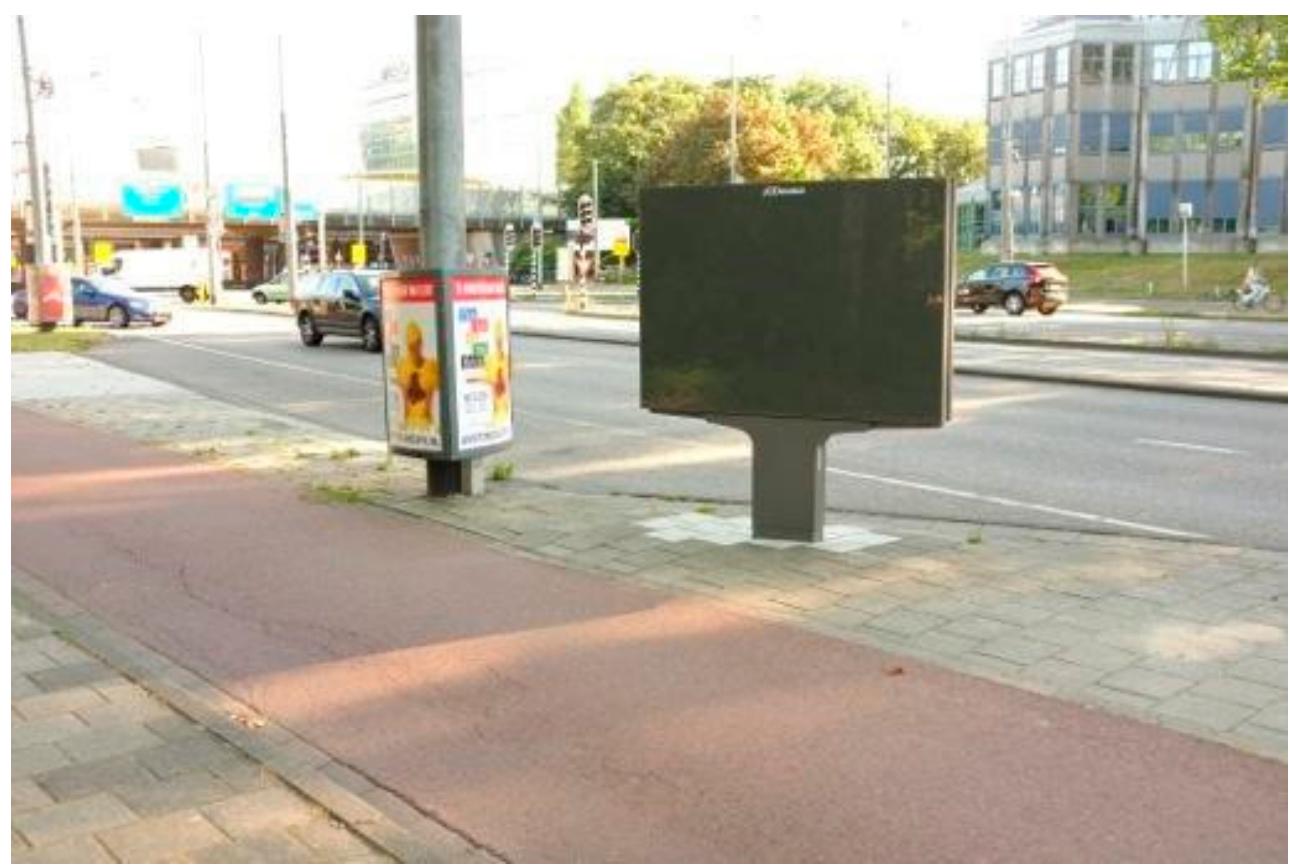

Figure 2. Digital outdoor advertisement screen located midway along the section of Amstelveenseweg. The company JCDecaux owns the screen shown next to one of the many smaller static "4-sheet" posters owned by Centercom. 


\subsection{Research Design}

Due to the changing speed that sensory information is apprehended whilst cycling, how to best access moving participants is the subject of current methodological debate [30]. The pace and movement of cycling make it difficult to follow and talk to people without interrupting the experience itself, as well as inducing safety risks [8]. Video cameras were instrumental in capturing the movement of cycling. Footage was captured with two cameras. One was attached to the handlebars of the bicycle of participants, directed at their faces to capture expressions and visual attention of their surroundings. The camera on the bicycle was discrete in size and did not interfere with the operation of the bicycle.

Footage was paused, slowed down, or replayed with participants, enabling discussion between researcher and participant of why their focus varied-referred to as "seeing there" [12]. Pow [31] argues that it is often hard for people to express their experience of senses other than vision due to the limited vocabulary available for the nonvisual dimensions. Video, however, opens up aspects of movement for dissection and allows participants to articulate the connections between sensory experience, context and place; previously difficult to access. Rather than in intellectually rooted ways, video-assisted interviews allow subjects to talk through sensorial experience and a give vocabulary for the "unspeakable". Video bridges the gap between embodied experience and language [32]. The camera's Wi-Fi function meant that footage could be immediately shown on our mobile phone. Unlike an eye-tracking setup, this was not aimed at objectively tracking the number of advertisements seen, but bringing further vocabulary to participants in interviews (see e.g., [12], for rhythms of breathing and pedalling that became more visible on video combined with follow up interviews). The second camera was mounted on one of our bicycles, tracking participants from behind. This camera supported the analysis of journey rhythms, scrutinising pauses, acceleration and flows, waiting, improvisation or conformity and rule breaking [32]. The audio-visual element of the video enabled participants to identify habitual or unconscious moments of the ride and the related sensory experience: "feeling there" [12]. With our ability to observe spatial practices in motion, DeLyser and Sui [30] (p. 296) argue to overcome reliance on "after-the-fact, stabilized retellings".

Two groups of participants were used: First, commuting cyclists served as the study group, generating insights into daily responses to Amstelveenseweg. Matching sample sizes of similar qualitative studies examining cycling (e.g., [14]), twenty participants were interviewed, half male and half female, spanning an age range of 18 to 55, of varying socio-economic backgrounds. Interviews were conducted throughout June and July 2014, which may have influenced the ease of gaining interviews outside. Due to the impetus to get to work on time, we approached cyclists after work when time was less of a constraint. It should be noted that by selectively examining commuters during traditional hours, we precluded those that work during non-traditional hours, who could have very different perceptions of the commercial parts of the environment. For example, those travelling in the darkness perceive and engage with the landscape in a notably different manner, forming unique embodied experiences [10].

Participants were chosen on the street at both ends of the route, by approaching them at a safe point on the pavement. The reason for examining both directions was to ensure a broader spectrum of employment sectors, as well as capturing any important differences in the environment of one direction over the other. Once pre-screened to determine if commuters, informed of the purpose of the study, had given consent, the camera was mounted to their bicycle. The cyclist was told to ride as he/she normally would and informed that we would catch up after the ride, where the interview would commence at a safe point further down. No reference was given to advertising specifically, as this may have influenced their gaze when cycling. It should be noted however, that there is the chance that demand characteristics [33] could influence the behaviour of the cyclist due to the overt methods used. Based on the concepts of everyday rhythms, mobility and sustainability literature, open-ended questions were formulated to gain relevant insights. Interviews were conducted straight after the cycle ride, ensuring the experiential details were fresh in the memories of the participants. Interviews were semi-structured with a constant focus on respondents' perceptions of the journey through the 
selected area, lasting between 20 and 40 minutes. Through open-ended dialogue with respondents, this approach provided us with the necessary insights and understanding of how sense of place is developed through on-going experiences (following a similar practice adopted by other qualitative research studies examining place $[8,34])$.

Second, interviews with four outdoor advertising professionals operating in Amsterdam were conducted. We spoke to senior executives from the largest outdoor advertising agencies in Amsterdam: Clear Channel, Exterion Media and Centercom. These companies used the research technology offered by the company Buitenreclame-onderzoek, who we reference in relation to existing research on cyclists' response to ads. These expert interviews gave us important background information on the characteristics of the route, insights into the advertising industry as a whole and how Amsterdam differs from other cities.

The audio-recorded interviews were transcribed and examined for commonalities and differences in the data by continually reading the interview transcripts [34]. Primary concepts that guided the analysis of the data were daily rhythms, awareness of advertisements and purchasing habits, mobility practices and embodied experience. After transcribing the interviews, the material was open coded for further investigation. This provided greater contextualisation of the concepts and helped decipher the meaning of statements.

\section{Results}

This section explores the embodied experience of daily rhythms and routines from the perspective of participants cycling along the Amstelveenseweg route. The embodied experiences of these rhythms are individualised constructions and are therefore different between participants. The subsequent results highlight both common characteristics and certain tendencies, as well as differences between them. The examination deals with various aspects of the journey that influence or are related to outdoor advertising.

\subsection{Timetables, Mood and Repetition}

The following examples illustrate how the scheduled rhythms of daily commuting interact with the cyclical rhythms of weather, nature and the body to produce distinct moods. The way people feel whilst cycling has profound implications for how receptive they are to environmental cues, such as advertisements. Participants noted the differences between cycling along the route in the morning versus the evening. Mornings were a time of alertness and calm for some, or hurried rush for others, depending on their timetable. Jana (25) explained: "in the morning I am more alert and can think to really watch it (the advertisement) ... also thinking I can watch it the next morning ... but when I go home, I am more like ... I don't bother, just go home now". Weep (33) on the other hand found that "in the morning I have to get there on time, whereas in the evening there is no ending time". Advertising Spokesperson 2, who cycled through Amstelveenseweg every day, explained: "yeah I think that you are empty at the end of the day, so I think it's a more relaxed mode ... in the morning I drop the kids off at school ... it is more stressful in the morning to get there on time to your appointment and be at work an extra thing at that moment where advertising will not catch you ... you are more open for it in the evening". As Mort [35] argues in relation to consumers: "we carry a bewildering range of different, and at times conflicting, identities around with us in our heads at the same time. There is a continual smudging of personas and lifestyle depending on where we are (at work, on the high street) and the spaces we are moving between". These moods represent a certain value to advertisers, as they can be used to direct their attention toward products being promoted. It becomes contentious, however, when personal data (i.e., phone data) provide digital outdoor advertisers with data points that can predict behaviour and show people customised messages. By responsively customising and changing space in real-time, fixed notions of place are reconfigured and place becomes more fluid [3]. Urban mobility for cyclists is framed by what Cronin [23] refers to as part of an increasing move toward temporally quantified spaces, with "personalised seductions" [3]. 
By using the same route, daily repetition led many to incrementally learn [17] from the environment in which they cycled. Diversity and change were available from alterations to the physical environment. The experience of change, such as different advertisement signs, generates a mark in time, connecting personal rhythms with the commercial rhythms dictated by marketing objectives.

Weep (33) reflected that "when I was cycling there every day I would notice when they (advertisements) change". The repetition of route features also reinforced memories; Annie (21) explained "one time I even saw a Japanese musician ... all around town ... and I really wanted to find out how his music was so I kept trying to remember his name". Forgetting advertisements was also a driving force to become more aware on following journeys in order to grasp further details of advertisement image and text, for example, Paul (43) explained: "when you go the other way on the other side (homeward) you have four or five by the railway station - so that is nice. But otherwise my mind can't remember. But if they are nice I will take a photo". Paul engaged with the environment with regard to advertisements, and he became attuned to the placement of different types, amounts, sizes and images. These examples illustrate McFarlane's [17] concept of "incremental urbanism", explaining how everyday routines of mobility such as cycling help continuously map travel routes via repetition. The consequence being that "the monotony of actions and of movements, imposed structures" [36] upon cyclists creates an on-going sense of expectation, and arguably, the trust and comfort needed for brand preference by advertisers. Degen et al. [4] found similar experiences of commercial landscapes of those who frequented their local shopping mall. Eventually they gained such familiarity with the centres that it fundamentally affected their experience of the landscape.

Despite the repetitive effects of advertisement exposure in increasing memory encoding, the 80+ advertisements along the route also dampened the intensity of how the advertising landscape appeared to the cyclists interviewed. Ironically, the frequency of advertisement placement (almost every 10 metres) worked to desensitise cyclists to their presence due to the lack of environmental contrast. For example, Beitske (36), who cycled along the route every day to commute, described how she had begun to operate on "automatic pilot" and tended to notice less "because I am just in my mind or talking to colleagues". Through repeating the same journey every day, full awareness of surroundings becomes secondary to other engagements (see for instance the bottom right picture in Figure 1 where a participant can be seen talking on the phone while cycling). Through repeating the same journey every day, full awareness of surroundings becomes secondary to other engagements, leading many participants to a "blasé attitude" [22], or a lowered sensitivity of their perceptual memory [21].

The perception of weather conditions changed the way participants felt cycling, inducing bodily sensations connected to certain impulses. For example, Jana (25) attributed "a lot of difference ... [to] the moment"; sunny weather provoking her to go to "Keti Koti festival" (advertised on Amstelveenseweg) and rain or snow the opposite. Scarlett (22) further explains, "when it's shitty I am just staring and when it's nice weather and just chilling on your bike I will look more around". An interviewed advertising-agency spokesperson explained the importance of how one feels whilst cycling and the weather: "the moment how you feel, maybe also the weather, that always influences the behaviour of people in that area. I think when it's nice weather, everyone looks around ... everybody is happy" (Spokesperson 2). Many participants expressed their openness to looking around as a result of sunny weather, which was the case during our rides, taking place in summer. We do not wish to state that warm weather will have the same effect for all cyclists, but that seasonality and weather holds potential to change the receptivity to certain advertising. With advances in digital outdoor advertising, the accuracy of screens linking to weather data was demonstrated by summer-related alcoholic drinking. Climate data activated messages were shown only when the temperature reached +21 degree Celsius. A targeting strategy was informed by consumer research that finds that media is both more effective and efficient if it is linked to weather data, as found by Cronin [1]. 


\subsection{Crowded Points and Continuous Stretches}

When looking back on the video footage with participants, the way in which they had to navigate the built environment surrounded by the changing elements of Amstelveenseweg showed that proximity to other cyclists was a constant possibility, particularly at traffic lights. Overtaking other cyclists was prevalent among most participants. Jana (25) always went "past everybody, because ... when you go during traffic hours, it is very busy. You have these groups; they are really annoying ... they try to make you go slower" (Figure 3 left picture). Once other cyclists had been passed and a straight path gained, the increase in speed reduced the amount of advertisements noticed. Raphael (25) compared the difference of cycling and walking on the route as being "much more different. When you are walking you notice things more. When you are cycling, everything is pretty much a blur". Despite this, the frequency of roadside "4-sheets" along the route still provoked cyclists' attention. Weep (33) highlighted the inevitability of roadside advertisements becoming part of her perceptual focus: "it is your natural gaze, I think it is hard not to look at them and notice them, they are every ten metres apart". In this sense, for participants in our study, different modes of cycling such as maintaining consistent movement framed how the landscape was perceived, contrasting with the "shopping look". The "manoeuvring look" [4] was adopted, distanced from the surrounding advertisements, and concerned with manoeuvring through the cycle path and traffic specific to the route.

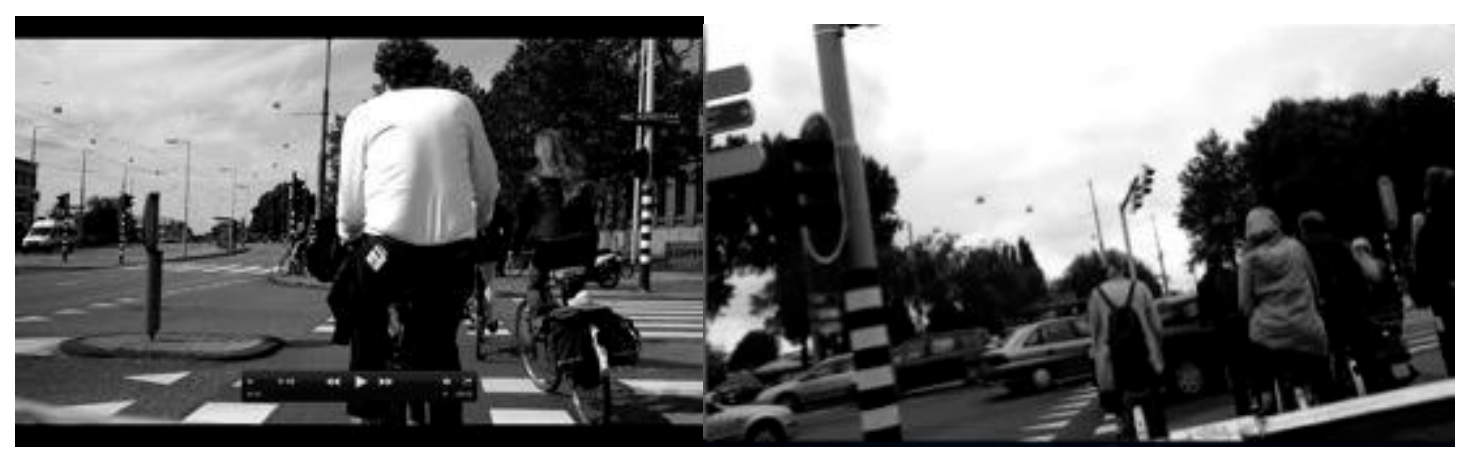

Figure 3. The left picture shows participant, Jana (25) (to the right of the photo), overtaking slower cyclists around her by weaving through a set of people. The right picture shows commuting cyclists waiting at the busy cross-point just after the Amstelveenseweg Metro station.

The desire to maintain momentum while cycling provoked many to informally cross through red lights as a way of preventing interruptions. Subsequently, the intended "dwell time" designated to these locations for cyclists to stop and view advertisements was reconfigured through alternative spatial practices. In this sense, particular ways of cycling such as maintaining consistent movement informed how the landscape was apprehended. The way this took form amongst participants in our study was evident for those whose gaze of the advertising landscape was unfocussed toward specific advertisements, and instead focussed on manoeuvring through the cycle path, navigating the rhythms of traffic specific to the route. As Jeanne (19) mentions, however, certain points-i.e., the EFA building-provoke more informal crossings than others: "nobody uses it (traffic lights), everybody just cycles through". Because two of the four crossing points are connected to a highway, being more dangerous, they necessitate stopping for most cyclists. Accordingly, the "16-sheet" billboard (Figure 4 right picture) placed here was engineered to deal with the larger and more static numbers of cyclists. An advertising agency spokesperson highlights this from first-hand observations: "I think the big sign ... with the Volvo ad will catch your imagination when you are standing still and can look around ... people are more open to absorbing information then ... toward the traffic lights you notice more, because your speed slows and you look around" (Figure 4 right picture and top left Figure 5) (Spokesperson 2). Larger ads such as this provoke distraction at crossing points, combined with informal crossings, this may have a higher hazard potential, as pointed out by Birdsall [37]; 
particularly along the Amstelveenseweg cycle route with illuminated digital screens (Figure 2, right of picture). Elsewhere on the route, at peak commuting times, certain advertisements, such as the pillar wraps (Figure 5 bottom right picture), became less noticeable due to pedestrians. Jeanne (19) notes how the chaos affects her attention: "the metro station it is quite difficult because there are a lot of people passing and you have to watch out because when there is a metro coming people are running". We can conclude that the rhythm of cycling changes depending on the layout of the route and the practicalities of negotiating traffic, meaning that visual attention of cyclists differs towards advertisements depending on specific moments during the route.

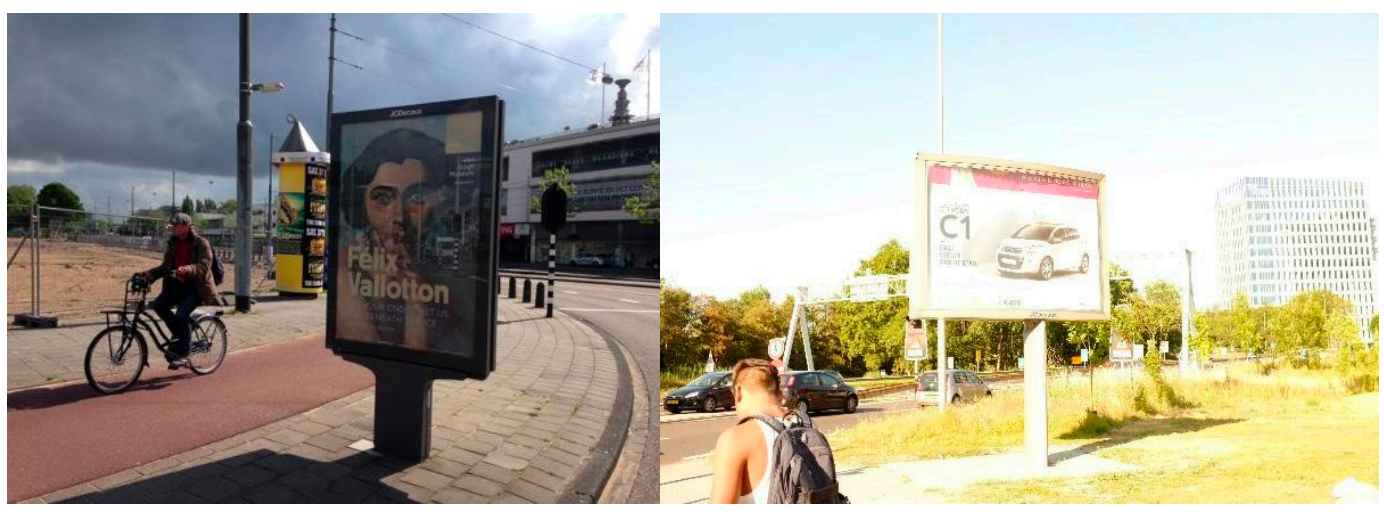

Figure 4. Left picture: cyclist passing two different outdoor advertisements formats owned by Centercom (left of left picture) and JCDecaux (right of left picture) beside the large construction site located at the end of the section of the route examined. Right picture: cyclist waiting at traffic light adjacent to large 16-sheet billboard.

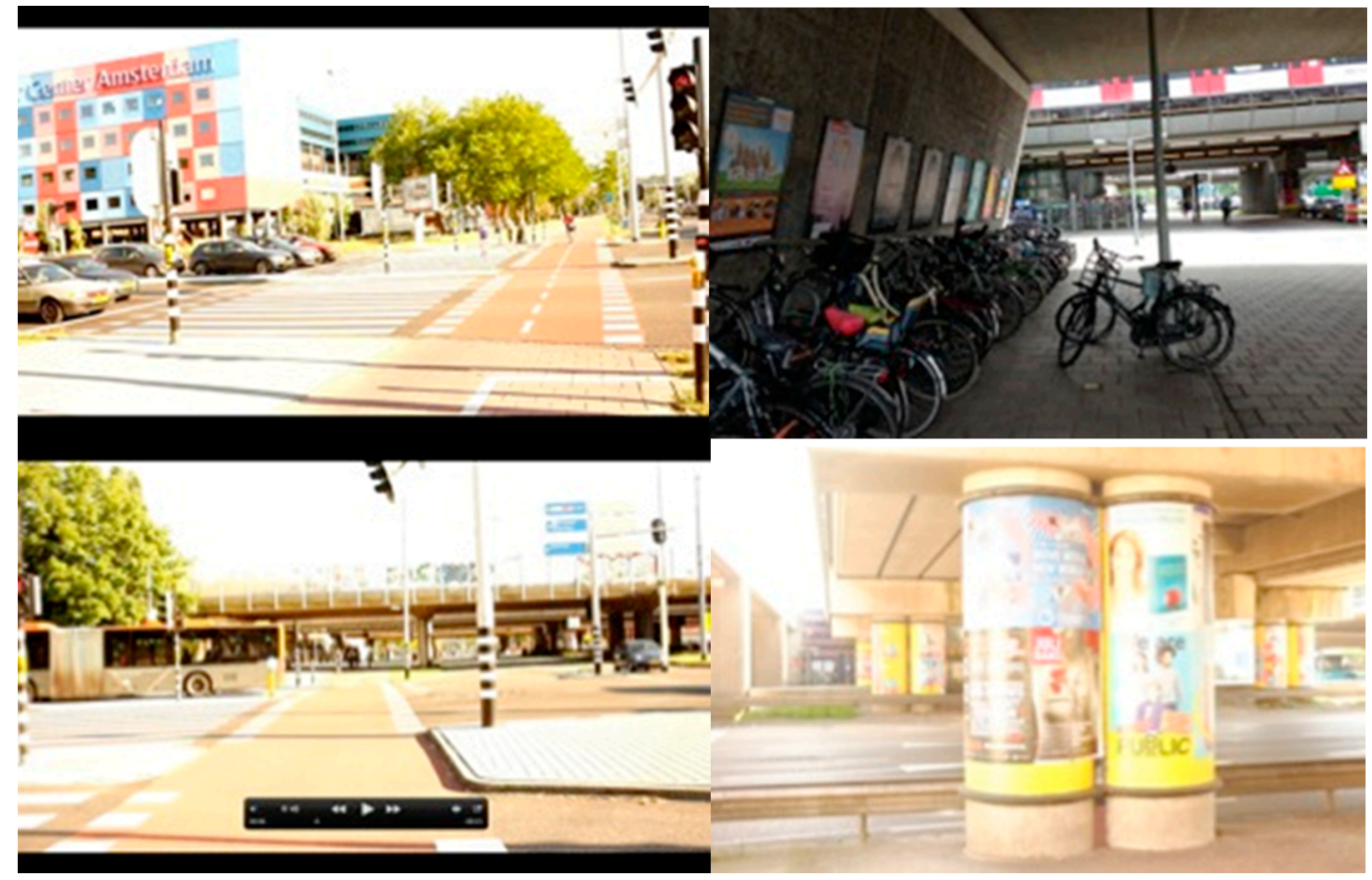

Figure 5. The top left and bottom left picture show the two major busy crossing points that force cyclists to stop (and view ads static). Top and bottom right pictures show the advertisements that can be seen under Amstelveenseweg metro station: pillar wraps on one side, and bicycle stand ads facing cyclists as they lock their bikes. 
On the other hand, incremental learning also formed an on-going changing rhythm, where commuting cyclists learned not to encounter outdoor advertising. Some participants learned not to go via Astelveenseweg, using alternative routes to work, unsettling the monotony of this everyday experience, and avoiding the chaotic rhythms of traffic, noise, pollution and advertising. As Jeanne (19) elaborated: "it is not the nicest route, like I have considered other routes because they are nicer". The "uninspiring" features that are observed along the Amstelveenseweg road also made participants aware of the built parts of the city that they enjoy. Fiona (22) went as far as to say that Amstelveenseweg was "just like a construction site (Figure 4 left picture), you feel as though you are not inside the city". By relating experiences of the peripheral area of Amstelveenseweg to the centre of Amsterdam, participants generated their own unique relational connection with the urban space through mobility. Through mobility, commuting cyclists adapted by learning to navigate the urban routes containing advertising, and at other times, tactically learning [17] to avoid them altogether. As discussed, this has implications for sustainable urban policy considerations for urban design and limitations to the advertising volume in cycle routes.

\section{Discussion and Conclusions}

This research has drawn attention to the way in which urban landscapes generate meaning and distinctions from the movement of cycling. Features of commuter landscapes, such as advertisements, take on different characteristics through rhythmic cycles of change, unique to the social and cultural contexts of Amsterdam. Within the case study area, the frequency of the advertisements and the positioning along the cycle paths-low down, faced toward the line of sight of cyclists, rather than cars-reflects the intentional engineering of advertisements to target cyclists. This type of strategy is a result of the cultural significance of cycling in Amsterdam, and the knowledge that such changes will enable advertisers to benefit from more targeted mechanisms.

The use of video is a developing field of enquiry for understanding fleeting aspects of mobility [30]. We used video in order to capture visual attention and bodily engagement with cycle paths. With a lack of protocols to use, a great deal of trial and error was necessary for successful results. The application of filming cyclists in cities with bicycle infrastructure or popularity of cycling different to Amsterdam will present its own unique safety issues, adaptations and challenges. Future research aimed at understanding the role of the body in perceiving advertising, and the landscape more broadly, is encouraged through this methodology.

Previous research that has applied the theoretical framework of urban rhythms to cyclists in cities $[12,14]$ has yet to consider how cyclists connect and overlap with the distinct rhythms of landscapes concentrated with outdoor advertising. We have shown this in several areas.

The repetition of cycling on the same route to commute resulted in not simply recalling or forgetting advertisements, but incrementally learning urban landscape features. The advertising spokespersons interviewed revealed that the advertisements along Amstelveenseweg operated within 2-week campaign cycles. The cyclists interviewed did not demonstrate a conscious awareness of these exact time frames, but instead an embodied synchronisation with the rhythms of advertisement change implemented along the route. The high concentration of smaller roadside advertisements also worked against the "synchronisation" of advertisement rhythms with commuting rhythms, as some participants became desensitised to the lowered environmental contrast, reducing the sensitivity of their perceptual memory [21]. These divergent yet connected modes of experiencing the landscape are not intended as a typology; instead they point out the diverse and complex ways that the commercial aspects of cities are visually engaged with. Rather than enticed by a "hypnotic spectacle" [5], they are grounded in context-specific spatial references, structured by personal rhythms. In addition, the linear rhythms of commuting daily by bicycle connected with the cyclical rhythms of weather, nature and the body to produce distinct moods that had implications for responses to advertisements.

Because of the complex interplay of navigating the road and its users, attention was at times distracted from the roadside advertisements, or by them, disrupting the level of momentum achieved. 
It was very important to cyclists that informal crossings were frequent, reconfiguring the anticipated "dwell time" [1] accorded to outdoor advertisement locations. These specificities of the route, when linked to particular temporal rhythms (the congested feeling of crossing points during rush hour), afforded their own place-temporalities, with different ways of visually understanding the advertising landscape. Those whose schedules were aligned toward consumption rhythms of making the opening hours of shops exhibited a "shopping look" toward commercial elements of the landscape. Equally, the reconfiguration of navigating the urban routes containing advertising was also illustrated by several of the cyclists examined, who "tactically learned" [17] to commute and cycle through alternative routes not containing advertising by adjusting their temporal rhythms.

We argue that the multi-sensory experience of cycling is far too particular to clump cars and pedestrians together to classify visual responses to roadside advertisements. For example, the subtleties of movement [38], limited sensory processing [8], different proximity to ads as well as varying visual obstruction from other cyclists. Participants highlighted walking as a separate engagement with the city, which generated place-specific associations [25] with advertising in urban space. This difference was also explained by the specific cultural meaning that walking has for residents of Amsterdam compared to other cities [27,39]; walking being more leisurely.

By examining the distinctive embodied experience attributed to cycling along Amstelveenseweg, critical questions are raised. Following the increased public-private partnerships developing in contemporary cities [2], the interest in creating a pleasurable urban environment could well become part of a discussion between advertising agencies and urban authorities. Iveson [2] (p. 164) highlights that rather than the problem being "too much advertising" it is rather, questioning the way public-private partnerships are set up between advertising agencies and local authorities. In many cities, partnerships have been premised on restricting access to public control of public media (i.e., graffiti, flyers, posters, etc.) as well as monetising street furniture and funding infrastructure projects with the potential for housing advertising, usually aimed at bus and train stops. Future research could also explore the necessity to integrate green features along cycling commuter routes, as a way of bringing solutions to achieving a sustainable urban space that makes use of the investment brought by advertising for cyclists as well as other urban citizens. As it is the case that the amount of cyclists in Amsterdam represents such a large captive audience for advertisers, there is certainly political leverage for discussions concerning the regulation of urban space that advertisers have access to shaping, and the citywide landscape. Indeed, cyclists may wish to resist and challenge the current access advertisers have to the landscape. Cycling has greater potential for sustainable growth when citizens are given knowledge and awareness of how and why cycle routes have been designed. Drawing attention to the variable ways in which specific routes are experienced for cyclists at the embodied level highlights city-level issues for policy makers concerned with what constitutes a flourishing city. Urban planning decisions should consider the effects that mono-featured advertising environments have on the senses, which have the potential to undermine the restorative, relaxing and pleasurable benefits of cycling.

The ability to precisely target commuters in urban spaces based on the idea of consumption moods, is being expanded through the use of consumer data linked to digital outdoor advertisement screens. Live data feeds such as climate variables, live events and interaction with mobile devices, are making temporal synchronisation with urban rhythms calculated [3,23] and aligned in a way never seen before. Precision in data-led targeting is extending those environments designed for commercial purposes (i.e., shopping malls), described by Biehl-Missal and Saren [40] as "atmospheres of seduction". Questions may be raised as to whether the increase in digital outdoor ads will structure urban spaces in a way that becomes invasive, precluding consent by users of public space. It is yet to be determined if it is more favourable to see advertisements digitally synchronised with personal rhythms, serving arguably more relevant messages to accurately matched audiences, rather than a cascade of meaningless signs. Given the fact that digital outdoor screens are now being introduced specifically to cyclists' commuting routes in Amsterdam, the nature and experience of commuting are likely to change dramatically. These "temporally quantified" [23] spaces benefit from the desensitisation of those 
exposed to commercial environments, aligning people's daily rhythms in a subtle yet ever-present way. From an experiential perspective, questions arise regarding if the movement and illumination associated with these screens become a hazard [37] to cyclists if implemented in busy and congested areas that require careful attention. Advertisers hold data and research on how many cyclists pass these points. Little discussion with local authorities is had over how this data could be used by the local government to prevent accidents, as well as gain a fuller picture of how cyclists navigate different routes.

At the wider level, having aimed our focus at one of the most affluent areas of Amsterdam, the concentration and quality of advertising here was by no means a coincidence. The abundance of corporate business, wealthy surrounding neighbourhoods and educational excellence serves to attract advertising, but also to generate revenue for local authorities through the partnership deals to acquire advertising space. The result being that advertising sites such as bus stops, metro stations and cycle paths receive the necessary investment for proper maintenance and renewal. The circumstances of less affluent neighbourhoods, who are of secondary value to advertisers intending to target affluent audiences, in turn become at risk of neglect by local authorities who rely on such partnerships. Sustainability research ought to consider how this process operates. Investigating the personal experiences of cyclists across different neighbourhoods provides a valuable insight into these disparities.

Author Contributions: Conceptualization, P.M.; methodology, P.M.; analyses, P.M.; writing—original draft preparation, P.M.; writing-review and editing, P.M. and M.H.; supervision, M.H. All authors have read and agreed to the published version of the manuscript.

Funding: This research received no external funding.

Conflicts of Interest: The authors declare no conflict of interest.

\section{References}

1. Cronin, A.M. Advertising, Commercial Spaces and the Urban; Springer: Berlin, Germany, 2010.

2. Iveson, K. Branded cities: outdoor advertising, urban governance, and the outdoor media landscape. Antipode 2012, 44, 151-174. [CrossRef]

3. Koeck, R.; Warnaby, G. Outdoor advertising in urban context: spatiality, temporality and individuality. J. Mark. Manag. 2014, 30, 1402-1422. [CrossRef]

4. Degen, M.; DeSilvey, C.; Rose, G. Experiencing visualities in designed urban environments: learning from Milton Keynes. Environ. Plan. A 2008, 40, 1901-1920. [CrossRef]

5. Allen, J. Ambient power: Berlin's Potsdamer Platz and the seductive logic of public spaces. Urban Stud. 2006, 43, 441-455. [CrossRef]

6. Jirón Martínez, P. Repetition and difference: Rhythms and mobile place-making in Santiago de Chile. In Geographies of Rhythm: Nature, Place, Mobilities and Bodies; Edensor, T., Ed.; Ashgate Publishing, Ltd.: Farnham, UK, 2010; pp. 129-143.

7. Merriman, P.; Revill, G.; Cresswell, T.; Lorimer, H.; Matless, D.; Rose, G.; Wylie, J. Landscape, mobility, practice. Soc. Cult. Geogr. 2008, 9, 191-212. [CrossRef]

8. Spinney, J. Cycling the city: Non-place and the sensory construction of meaning in a mobile practice. Cycl. Soc. 2007, 2545.

9. Wylie, J. A single day's walking: narrating self and landscape on the South West Coast Path. Trans. Inst. Br. Geogr. 2005, 30, 234-247. [CrossRef]

10. Cook, M.; Edensor, T. Cycling through dark space: Apprehending landscape otherwise. Mobilities 2017, 12, 1-19. [CrossRef]

11. Böcker, L.; Dijst, M.; Faber, J.; Helbich, M. En-route weather and place valuations for different transport mode users. J. Transp. Geogr. 2015, 47, 128-138. [CrossRef]

12. Brown, K.; Spinney, J. Catching a glimpse: the value of video in evoking, understanding and representing the practice of cycling. In Mobile Methodologies; Springer: Berlin, Germany, 2010; pp. 130-151.

13. Jones, P. Sensory indiscipline and affect: a study of commuter cycling. Soc. Cult. Geogr. 2012, 13, 645-658. [CrossRef] 
14. Van Duppen, J.; Spierings, B. Retracing trajectories: the embodied experience of cycling, urban sensescapes and the commute between 'neighbourhood'and 'city'in Utrecht, NL. J. Transp. Geogr. 2013, 30, $234-243$. [CrossRef]

15. Stefansdottir, H. A theoretical perspective on how bicycle commuters might experience aesthetic features of urban space. J. Urban Des. 2014, 19, 496-510. [CrossRef]

16. McKenna, J.; Whatling, M. Qualitative accounts of urban commuter cycling. Health Educ. 2007, 107, 448-462. [CrossRef]

17. McFarlane, C. Learning the City: Knowledge and Translocal Assemblage; John Wiley \& Sons: Hoboken, NJ, USA, 2011; Volume 101.

18. Helbich, M.; Böcker, L.; Dijst, M. Geographic heterogeneity in cycling under various weather conditions: Evidence from Greater Rotterdam. J. Transp. Geogr. 2014, 38. [CrossRef]

19. Edensor, T. Geographies of Rhythm: Nature, Place, Mobilities and Bodies; Ashgate Publishing, Ltd.: Farnham, UK, 2012.

20. Skinner, D.; Rosen, P. Hell is other cyclists: rethinking transport and identity. In Cycling and Society; Routledge: Abingdon, UK, 2016; pp. 99-112.

21. Degen, M.M.; Rose, G. The sensory experiencing of urban design: The role of walking and perceptual memory. Urban Stud. 2012, 49, 3271-3287. [CrossRef]

22. Simmel, G. Money in modern culture. Theory Cult. Soc. 1991, 8, 17-31. [CrossRef]

23. Cronin, A.M. Mobility and market research: outdoor advertising and the commercial ontology of the city. Mobilities 2008, 3, 95-115. [CrossRef]

24. Kärrholm, M. To the Rhythm of Shopping-On Rhythmic and Territorial Stabilisations of Public Space in Urban Retail Environments; Lund University: Lund, Sweden, 2006.

25. Pike, A. Geographies of brands and branding. Prog. Hum. Geogr. 2009, 33, 619-645. [CrossRef]

26. Van Meurs, L.; Aristoff, M. Split-second recognition: What makes outdoor advertising work? J. Advert. Res. 2009, 49, 82-92. [CrossRef]

27. Stoffers, M. Cycling as heritage: representing the history of cycling in the Netherlands. J. Transp. Hist. 2012, 33, 92-114. [CrossRef]

28. Lee, R. 'Nice maps, shame about the theory'? Thinking geographically about the economic. Prog. Hum. Geogr. 2002, 26, 333-355. [CrossRef]

29. Bryman, A. Social research methods; Oxford university press: Oxford, UK, 2016.

30. DeLyser, D.; Sui, D. Crossing the qualitative-quantitative divide II: Inventive approaches to big data, mobile methods, and rhythmanalysis. Prog. Hum. Geogr. 2013, 37, 293-305. [CrossRef]

31. Pow, C.P. "Sense and Sensibility": Social-spatial Experiences of the Visually-impaired in Singapore. Singap. J. Trop. Geogr. 2000, 21, 166-182. [CrossRef]

32. Spinney, J. A chance to catch a breath: Using mobile video ethnography in cycling research. Mobilities 2011, 6, 161-182. [CrossRef]

33. McCambridge, J.; De Bruin, M.; Witton, J. The effects of demand characteristics on research participant behaviours in non-laboratory settings: a systematic review. PLoS ONE 2012, 7, e39116. [CrossRef] [PubMed]

34. Manzo, L.C. For better or worse: Exploring multiple dimensions of place meaning. J. Environ. Psychol. 2005, 25, 67-86. [CrossRef]

35. Mort, F. The politics of consumption. New Times Chang. Face Polit. 1990s 1989, 160-172.

36. Lefebvre, H. Rhythmanalysis: Space, time and everyday life; A\&C Black: London, UK, 2004.

37. Birdsall, M.S. The debate over digital billboards: can new technology inform drivers without distracting them? Inst. Transp. Eng. ITE J. 2008, 78, 22.

38. Seamon, D. Body-subject, time-space routines, and place-ballets. Hum. Exp. Sp. Place 1980, 148, 65.

39. Aldred, R.; Jungnickel, K. Why culture matters for transport policy: the case of cycling in the UK. J. Transp. Geogr. 2014, 34, 78-87. [CrossRef]

40. Biehl-Missal, B.; Saren, M. Atmospheres of seduction: A critique of aesthetic marketing practices. J. Macromark. 2012, 32, 168-180. [CrossRef]

(C) 2020 by the authors. Licensee MDPI, Basel, Switzerland. This article is an open access article distributed under the terms and conditions of the Creative Commons Attribution (CC BY) license (http://creativecommons.org/licenses/by/4.0/). 